\title{
A REESTRUTURAÇÃO PRODUTIVA E O FESTIVAL DE TESES SOBRE EDUCAÇÃO E QUALIFICAÇÃO PROFISSIONAL
}

Roberto Leme Batista ${ }^{\mathrm{i}}$

\author{
Renan Araújo ii \\ Universidade Estadual do Paraná - Paranavaí
}

RESUMO:

Este artigo é resultado das reflexões que realizamos em nossas pesquisas na Rede de Estudos do Trabalho - RET e, em nos Programas de Pós Graduação da UNESP (Marília e Araraquara). Pesquisamos as transformações no mundo do trabalho inerentes ao processo de reestruturação produtiva que impôs uma afirmação ideológica, segundo a qual, haveria uma importância da educação básica para a formação profissional dos indivíduos. Nesse sentido, ganha posição uma visão segundo a qual haveria uma centralidade da educação, sobretudo porque a esta caberia a formação da força de trabalho, desenvolvendo as "competências" para atender as necessidades do mercado. O debate atual no âmbito da sociologia do trabalho e da educação retoma antigas questões sobre o problema da qualificação, ao mesmo tempo, em que novas questões devem ser investigadas. No Brasil a ideologia da nova educação profissional, presente em diversos documentos oficiais que consolidam a legislação da educação e a nova institucionalidade da educação profissional, apresenta as denominadas competências como requisitos exigidos da força de trabalho como uma espécie de "consenso nacional".

Palavras-chave: Reestruturação produtiva, educação profissional, competências.

\section{A FESTIVAL OF RESTRUCTURING PRODUCTION THESIS ON EDUCATION AND PROFESSIONAL QUALIFICATION}

\begin{abstract}
:
This article is resulted of the reflections that we carry through in our research in the Net of Studies of Work - RET and, in in the Programs of After Graduation of the UNESP (Marília and Araraquara). We according to search the transformations in the world of the work inherent to the process of productive reorganization that imposed an ideological affirmation, which, would have an importance of the basic education for the professional formation of the individuals. In this direction, it gains position a vision according to which would have a centralidade of the education, over all because to this the formation of the work force would fit, developing the "abilities" to take care of the necessities of the market. The current debate in the scope of the sociology of the work and the education retakes old questions on the problem of the qualification, at the same time, where new questions must be investigated. In Brazil the ideology of the new professional, present education in diverse official documents that consolidate the legislation of the education and the new institucionalidade of the professional education, presents the called demanded abilities as requisite of the work force as a species of "national consensus".
\end{abstract}

Key-words: Productive reorganization, professional education, abilities.

\section{Introdução}

No Brasil, a partir da década de 1990, mormente a disseminação dos diferentes aspectos técnico-organizacionais, do deslocamento, fechamento e abertura de inúmeras empresas, da (des)regulamentação trabalhista responsável por institucionalizar novas 
formas de precarização do trabalho. No bojo dessas metamorfoses de cunho políticoeconômico-social, processo intimamente vinculado à emergência do complexo de reestruturação produtiva, ganhou vulto a discussão acerca da definição das assim chamadas "qualidades e atributos pessoais", que são "construídas" por meio da educação.

Contudo, a polêmica suscitada em torno do seu significado(s), da sua definição social propriamente, tem impulsionado uma gama variada de interpretações, quiçá de confusões, posto que sua semântica sugere um amplo leque de atribuições necessárias, e exigidas, para que os indivíduos garantam sua "empregabilidade".

Tal qual procuraremos demonstrar ao longo dessa exposição, não há consenso, muito menos clareza sobre o novo perfil de trabalhador exigido no contexto da reestruturação produtiva. A ideologia hegemônica, desconsiderando haver uma preservação das condições de alienação e estranhamento no trabalho, faz apologia desse processo, pois afirma que este é positivo para os trabalhadores, já que esses são convocados à participação e envolvimento, através dos CCQs e do trabalho polivalente e multifuncional.

Muitos analistas apresentam os "modelos" de formação profissional, ditos capazes de gerar os assim chamados "novos atributos", como passaporte para a construção, desenvolvimento e consolidação da cidadania, ou seja, não rompem com a perspectiva funcionalista do capital, pois reafirmam a visão "segundo a qual a sociabilidade é travestida em conjuntos de atitudes e comportamentos sociais que passam a constituir, junto com atributos técnicos e cognitivos, o novo rol de 'qualificações profissionais' demandados pela empresa 'moderna"” (Silva Júnior, Ferretti e González, 2001, p. 26).

Todavia, há uma concepção ideológica iii insistentemente disseminada na sociedade, pressupondo que as atitudes e habilidades - ou os novos atributos - que enfatizam o "aprender a aprender", "aprender a pensar", "aprender a ser", nos limites postos pelo capital no contexto da mundialização, garantem o sucesso do indivíduo. É como se antes da pedagogia do "aprender a aprender" - os trabalhadores não soubessem aprender, pensar e ser. Essa ideologia explicita a idéia de que somente "a educação funcionalista, subordinada aos interesses do Capital, oferece ao trabalhador as condições cognitivas para estar apto a pensar, a ser crítico, a resolver problemas, a situar-se, enfim, de forma inteligente, ativa e participativa no moderno mundo do trabalho" (Rummert, 1998, p. 29).

Analisando as "novas qualidades pessoais" requeridas pelo capital no contexto da reestruturação produtiva, Araújo (1999) afirma que a reestruturação produtiva gera a demanda por "novos 'atributos pessoais' [que] constituem-se como condição para que os trabalhadores se ajustem à nova estrutura organizacional das empresas" (Araújo, 1999, p. 19). Num contexto em que o capital passou a privilegiar as técnicas toyotistas, disseminando-se a máxima segundo a qual "um assalariado deve se submeter a uma avaliação permanente e a uma constante prova de sua adequação às atividades de trabalho, em que se baseia a também emergente "noção de competência"” (Ibid).

Araújo acrescenta que:

Entre as novas demandas por qualificação dos trabalhadores encontramos um grande e impreciso leque de qualidades humanas: iniciativa, espírito de equipe, capacidade de comunicação, sociabilidade, criatividade, disposição para aprender, curiosidade, disciplina, motivação, atenção, responsabilidade, estabilidade, confiança, autonomia, capacidade de cooperação, lealdade, comprometimento, competitividade, habilidade de negociação, capacidade de pensar, de decidir etc. (Ibid.).

Revista HISTEDBR On-line, Campinas, n. Especial, p.162-180, mai.2009 - ISSN: 1676-2584 
Evidentemente que na sua longa trajetória histórico-social, os indivíduos - no seu processo de hominização - necessitaram desenvolver novas destrezas, habilidades manuais e intelectuais reduzidas atualmente, de acordo com o jargão neoliberal, a "qualidades e atributos pessoais" para a realização do trabalho. Ocorre, porém, que em cada contexto histórico, em seus distintos momentos, considerando a forma específica da organização da produção social, os homens se viram diante da necessidade de encontrar respostas aos dilemas de como se colocar diante da produção de suas necessidades materiais e espirituais, da produção da vida propriamente dita.

Queremos ressaltar que, no contexto da reestruturação produtiva - toyotista - as "características pessoais" exigidas dos trabalhadores sofrem um redimensionamento, uma readequação, para se manterem funcionais à lógica do capital. Essas exigências de "novas qualificações" quando postas pelas complexas e heterogêneas inovações tecnológicas e organizacionais, no contexto da reestruturação produtiva, estão diretamente relacionadas com o contexto histórico, tecnológico e social em que se inserem.

Numa tentativa de apreender essas exigências, Ana Teixeira afirma que apesar dos múltiplos aspectos e da complexidade envolvidos nesta questão, é inquestionável a existência das mudanças nas qualificações requeridas para o trabalho industrial. Nesse sentido, afirma:

Essa mudança poderia ser sintetizada como perda de importância das habilidades manuais em favor das habilidades cognitivas (leitura e interpretação de dados formalizados; lógica funcional e sistêmica; abstração; dedução estatística; expressão oral, escrita e visual) e comportamentais (responsabilidade, lealdade e comprometimento; capacidade de argumentação; capacidade para o trabalho em equipe; capacidade de iniciativa e autonomia; habilidade para negociação. Essas novas qualificações poderiam ser organizadas em três grandes grupos: novos conhecimentos práticos e teóricos, capacidade de abstração, decisão e comunicação, e qualidades relativas à responsabilidade, atenção e interesse pelo trabalho (Teixeira, 1998, p. 177-8).

O processo de "modernização" decorrente da reestruturação produtiva é contraditório, pois, ao promover as mudanças no processo de trabalho, tornando-o mais complexo e menos repetitivo do que o trabalho especializado, de conteúdos simples e demasiadamente repetitivos na realização das tarefas, dos antigos postos de trabalho fixos, da forma de organização taylorista-fordista, para uma organização flexível do trabalho com rotatividade nas funções, passa a demandar maior participação e envolvimento do trabalhador no interior da empresa, pois, haveria maior interesse deste na realização do trabalho com menos monotonia e repetição, assim como com menor riscos de acidente de trabalho.

Além disso, é necessário considerar que a denominada autonomia do trabalhador nesse processo é extremamente relativa, pois, a sua participação e engajamento são estimulados apenas em torno dos interesses da empresa. Portanto, sua participação é estimulada, manipulada e controlada. O capital através dos Círculos de Controle de Qualidade absorve e incorpora apenas as sugestões que forem do interesse da empresa. Que autonomia fantasiosa é essa que impõe ao trabalho a jornada, o salário, o quê e como fazer?

Podemos afirmar que nesse processo há uma frustração do trabalhador, pois, à medida que se exige dele maior escolaridade, maior qualificação etc., gera-se a expectativa de uma certa satisfação no trabalho. Entretanto, o que se observa é o pânico em torno do 
desemprego, da possibilidade concreta da demissão a qualquer momento, do salário baixo, etc. Há ainda a angústia diante das disputas que os trabalhadores travam entre si para manterem-se no emprego e para serem promovidos na empresa, já que a solidariedade de classe anda em baixa, o que vale é a exacerbação do individualismo.

\section{As inovações tecnológicas e organizacionais e o impacto sobre a qualificação}

No contexto da reestruturação produtiva há um excedente de força de trabalho, um exército industrial de reserva, escolarizado, disponível no mercado, o que torna possível ao capital a estratégia de descartar os "problemáticos" e "inadaptados", que transitam continuamente entre o emprego precário e o desemprego, constituindo-se num mecanismo de pressão sobre os trabalhadores que se mantém no emprego. Em razão disso, Peña Castro nos lembra que o desemprego, como produto da crise do emprego, "deve ser considerado um componente funcional necessário da lógica empresarial de uso da força de trabalho, comandada por dois princípios inalteráveis: 1) o aumento da produtividade e 2) o pleno controle sobre o trabalho" (Peña Castro, 2001, p. 1).

Portanto, é necessário buscar um entendimento crítico das inovações tecnológicas e organizacionais e suas implicações sobre as relações de produção, sobre o processo de trabalho, assim como suas conseqüências na luta entre capital e trabalho. Portanto, trata-se de considerar as inovações tecnológicas e também as organizacionais como uma relação social e não como uma coisa natural. Nesse sentido, Teixeira afirma:

A tecnologia não é uma variável independente que atue de modo a determinar a gestão e organização do trabalho, sendo possível pensar em escolhas sociais alternativas relacionadas a emprego, qualificação e educação. As premissas neoliberais, defensoras da sujeição da sociedade à lógica do mercado e de um modelo de intervenção que privilegia a iniciativa privada em lugar do Estado se configuram, concretamente, na política e no planejamento dessas áreas quase como uma fatalidade (Teixeira, op cit, p. 167, os grifos são nossos).

Ana Maria Rezende Pinto (1994) examinando a relação tecnologia e educação, e as implicações da introdução da automação informatizada sobre o trabalho, afirma que o sistema produtivo tem demandado qualificação profissional que se expressa numa "policognição tecnológica", ou seja, demanda-se trabalhadores que tenham:

a) domínio dos fundamentos científico-intelectuais subjacentes às diferentes técnicas que caracterizam o processo produtivo moderno, associado ao desempenho de um especialista em um ramo profissional específico; b) compreensão de um fenômeno em processo no que se refere tanto à lógica funcional das máquinas inteligentes como à organização produtiva como um todo; c) responsabilidade, lealdade, criatividade, sensualismo; d) disposição do trabalhador para colocar seu potencial cognitivo e comportamental a serviço da produtividade industrial (Pinto, 1994, p. 40).

Portanto, é no contexto da reestruturação produtiva, sob a hegemonia da forma toyotista de organização da produção ${ }^{\text {iv }}$, que se configura no setor produtivo e também no de serviços, um processo de inovações tecnológicas e organizacionais, capazes de impor mudanças no uso da força de trabalho, flexibiliza-se a produção, reestrutura-se as ocupações, promove-se a integração dos diversos setores da empresa. Esse processo cria a necessidade do trabalhador "polivalente", "multifuncional" e "qualificado", pois o capital ao menos em nível de discurso - passa a valorizar os conhecimentos não vinculados ao trabalho prescrito tal como ocorre sob o fordismo. 
Analisando o problema do trabalho "qualificado", "polivalente" e "multifuncional", Antunes (1999) afirma que esse processo

faz aflorar o sentido falacioso da 'qualificação do trabalho', que muito freqüentemente assume a forma de uma manifestação mais ideológica do que de uma necessidade efetiva do processo de produção. A qualificação e a competência exigidas pelo capital muitas vezes objetivam de fato a confiabilidade que as empresas pretendem obter dos trabalhadores, que devem entregar sua subjetividade à disposição do capital (Antunes, 1999, p. 52).

\section{A constituição de um novo (sujeito) trabalhador}

A pedagogia do capital, no complexo de reestruturação produtiva visa a conformação e "preparação de um trabalhador mais adequado aos novos padrões de exploração" (Freitas, 1995, p. 126).

As mudanças nos padrões de exploração passaram a exigir novas habilidades dos trabalhadores, razão pela qual as classes dominantes e também o Estado colocam centralidade na educação básica (Duarte, 2001, p. 46).

Podemos dizer que a chamada crise do trabalho se constitui, na verdade, em uma crise do emprego assalariado. O desemprego e a precarização são as expressões mais visíveis do capitalismo no contexto de sua financeirização. Nesse sentido,

a chave para o entendimento da especificidade do novo modelo continua sendo a transformação das relações sociais de produção, caracterizadas pela transição da expansão material para a expansão financeira e do comando industrial nacional para o comando financeiro global sobre os processos de valorização e de acumulação do capital. E isso envolve mudanças na base tecnológica, na estrutura organizacional das empresas, na organização do processo de trabalho e no sistema salarial (Castro, 2001, p. 2).

Peña Castro parte da premissa de que no contexto da mundialização financeirizada há duas hipóteses extremas sobre as perspectivas do emprego, quais sejam: "fim do trabalho" ou "pleno emprego". São extremas porque não encontram guarida e sustentação nos fatos e muito menos "nas propostas das forças sociais organizadas" (Peña Castro, 2001, p. 3). Razão pela qual o autor volta sua atenção para três aspectos da dinâmica capitalista no atual contexto histórico:

i. o tipo de tecnologias e de organização do processo de trabalho adotado para elevar a produtividade e obter maiores volumes de produção com menor número de trabalhadores; ii. a estratégia empresarial de flexibilização ou precarização das relações de trabalho, que sustenta a carreira pela redução dos custos, atingindo níveis extremos nos países dependentes; iii. o regime econômico e político que dá sustentação ao novo modelo de inserção do país no capitalismo mundial, o qual impõe às periferias uma divisão do trabalho que oferece poucas ou nulas perspectivas de ampliação das produções mais empregadoras (Ibid.).

Peña Castro afirma ser necessário deixar de lado as especulações em torno das hipóteses extremas, pois, neste contexto, o que parece decisivo para a evolução do 
emprego é a vontade política das classes que vivem do seu trabalho. "A posição concreta destas últimas flutua entre a passividade e o pessimismo resignado e a oposição mais ou menos ativa, ainda minoritária, devido ao déficit de organização e consciência política do que está em jogo" (Ibid., p. 4).

O complexo de reestruturação produtiva instaura uma sociabilidade que difere da sociabilidade taylorista-fordista, por meio da desconstrução e desconcentração das classes trabalhadoras. Aprofunda o processo de subsunção real do trabalho ao capital, criando novos mecanismos de controle, disciplina e vigilância de novo tipo. A ideologia do toyotismo convoca os trabalhadores a serem parceiros, a associarem-se ao capital abrindo brechas para que este fale diretamente ao seu "coração". O capital atua no sentido de criar um "cidadão produtivo" que no mundo da mercadoria se vê convertido à figura do "consumidor consciente e exigente". Como afirma uma das ideólogas do PLANFOR v ao dizer que "cidadão consciente, consumidor exigente, trabalhador reivindicativo são facetas praticamente impossíveis de se dissociar no indivíduo" (Leite, 1997, p. 162).

Vemos, pois, que o capital exige disciplina, vontade, envolvimento e participação do trabalhador. Nesse sentido, "o trabalhador de que o capital necessita é aquele que é capaz de dar resposta, pronta e adequada, às situações que possam ocorrer no ato produtivo. Requer-se, portanto, o trabalhador polivalente" (Dias, 1999, p. 125).

Razão pela qual, Dias acrescenta:

Ganhar corações e mentes dos trabalhadores significa, portanto, desestruturar-lhes a identidade de classe. A perspectiva do 'desaparecimento' das classes, a proposta implícita de um pacto social automático no cotidiano e, portanto, despolitizado e despolitizante, requer não a mera reafirmação de dogmas, mas a construção da identidade das classes trabalhadoras, respeitada a sua diversidade, conhecidas as suas lutas, linguagens e tradições (Ibid).

Em suma, esse contexto é capaz de provocar mudanças que atingem o universo político, econômico e cultural articulando mudanças nas bases técnico-científicas - ou seja, na base física - com novas formas de organização e gestão da produção. Esse fenômeno acarreta mudança na forma de ser dos trabalhadores, constituindo-se num processo real de captura e manipulação da subjetividade da classe-que-vive-do-seu-trabalho, alterando sua forma de ser "no nível da produção, ou, mesmo no plano administrativo, baseado numa 'temporalidade social' - em um contexto de uma nova constelação de relações sociais e uma nova cultura institucional da empresa -, mas que se embasa num 'tempo real' e em um "conhecimento por simulação" (Silva Júnior, 2001, p. 259).

A reestruturação do processo produtivo contemporâneo implica, pois, numa rearticulação estrutural do capital que historicamente antagônico ao trabalho, faz com que concomitantemente à sua insaciável busca pela acumulação, se redesenhem as diferentes esferas de produção-reprodução do ser social. As mudanças não se operam apenas no âmbito do processo de trabalho, é necessário vasculhar as relações existentes entre reestruturação produtiva, neoliberalismo, reforma do Estado e outras ações do capital.

O complexo de reestruturação produtiva assentado nos paradigmas inerentes ao toyotismo enquanto momento predominante, implica em alterações radicais no mundo da produção à medida que impõe um novo paradigma organizativo da própria empresa, "tais como o just-in-time/kanban, o controle de qualidade total e o engajamento estimulado, levado a efeito pelas corporações japonesas, [que] assumiram nova significação para o capital, não mais se vinculando às suas particularidades concretas originárias" (Alves, 2000, p. 31-2). 
Dentre as mudanças, temos aquelas que dizem respeito à base física decorrentes da incorporação dos avanços científicos resultando em plantas industriais com equipamentos complexos e sofisticados de microeletrônica. Essa realidade exige trabalhadores que possuam não apenas habilidade específica para sua operação, pois é necessário saber prever eventuais falhas, fazer reparos de emergência e tomar decisões relativas à produção, para evitar que as atividades produtivas sejam interrompidas, provocando prejuízos ao capital.

É neste contexto que afinados, governos, entidades empresariais e mesmo segmentos do movimento sindical difundem a idéia da robustez econômica assentada no crescimento sustentável posto que este deriva da associação de elementos que se interconectam: a saber, educação, produtividade, competitividade e globalização.

Há, nesse sentido, uma reincorporação da teoria do capital humano - agora uma neoteoria - pois, para o pensamento hegemônico a relação entre educação, produtividade e competitividade é inquestionável. Em consonância com esta nova retórica-necessidade incrustada no âmbito do Estado e das instituições dos empresários e trabalhadores, ganham relevo as discussões relativas ao fenômeno do déficit educacional identificado recentemente como sendo o "fator" determinante do estrangulamento do crescimento econômico.

Posto, assim, agora o que importa é adaptar-se e integrar-se ao mercado global. Documentos produzidos em nível de governo e de instituições dos empresários e também dos trabalhadores, dão conta da necessidade de elevar a escolaridade e o nível de qualificação dos trabalhadores, para que estes possam operar os equipamentos modernos, de base microeletrônica, capazes de melhorar a competitividade dos produtos do país. $\mathrm{O}$ saber e o conhecimento exigido dos trabalhadores são apontados como o saber escolar, que, segundo o discurso governamental, empresarial e segmentos sindicais, embasam, dão fundamentos aos princípios formados pelo binômio da competitividade-produtividade.

Nesse contexto atribui-se uma centralidade à educação básica, que passa a ser tratada como prioridade, pois sem ela não se produz o saber necessário exigido pela produção. Ao tratar o problema da educação básica, o pensamento hegemônico estabelece também qual a qualificação profissional que requisitam, que perfil de homem e de trabalhador o mercado exige.

De fato, o advento da reestruturação produtiva exigiu um trabalhador com novo perfil profissional-social. Segundo a literatura hegemônica, a nova base técnica e as novas formas de gestão exigem que o trabalhador seja capaz de aliar qualificação (saber-fazer) a um conjunto de atributos pessoais (saber ser). A lógica que impera é o pressuposto ideológico da pedagogia do "aprender a aprender", fundado na pedagogia e/ou ideologia do modelo de competência.

O debate sobre este tema, após a década de 1950 e, sobretudo no contexto atual, produziu uma ampla literatura, que nos é impossível abordar nos limites desse trabalho, razão pela qual abordaremos rapidamente apenas a concepção de qualificação como competência, pois entendemos que há um revigoramento desse conceito pelo capital no contexto da reestruturação produtiva.

\section{A afirmação da noção de competência}

É no contexto de desenvolvimento do complexo de reestruturação produtiva que emerge a noção de competência, que atende, pelo menos, a três propósitos: 
a) reordenar conceitualmente a compreensão da relação trabalhoeducação, desviando o foco dos empregos, das ocupações e das tarefas para o trabalhador em suas implicações subjetivas com o trabalho; b) institucionalizar novas formas de educar/formar os trabalhadores e de gerir o trabalho internamente às organizações e no mercado de trabalho em geral, sob novos códigos profissionais em que figuram as relações contratuais, de carreira e de salário; c) formular padrões de identificação da capacidade real do trabalhador para determinada ocupação, de tal modo que possa haver mobilidade entre as diversas estruturas de emprego em nível nacional e, também, em nível regional (como entre os países da União Européia e do Mercosul) (Ramos, 2000, p. 39).

Tanguy e Ropé (1997) apropriam-se da definição de competência constante do Dicionário Larouse Comercial (editado em 1930), porque este "ressalta uma das características essenciais da noção de competências: a competência é inseparável da ação" (Tanguy \& Ropé, 1997, p. 16). Eis, a definição apresentada pelo dicionário:

Nos assuntos comerciais e industriais, a competência é o conjunto de conhecimentos, qualidades, capacidades e aptidões que habilitam para a discussão, a consulta, a decisão de tudo o que concerne seu ofício (...) Ela supõe conhecimentos fundamentados (...) geralmente, considera-se que não há competência total se os conhecimentos teóricos não forem acompanhados das qualidades e da capacidade que permitem executar as decisões sugeridas (Dicionário Larouse Comercial apud Tanguy \& Ropé, 1997, p. 16).

Na seqüência, as autoras afirmam o entendimento de que colocada dessa forma "a competência é um atributo que só pode ser apreciado e avaliado em uma situação dada". Que, entretanto, a forma corriqueira dos usos que se faz dessa noção não permitem uma conclusão definitiva e conclusiva acerca da mesma. Afinal, a noção de competência "se apresenta, de fato, como uma dessas noções cruzadas, cuja opacidade semântica favorece seu uso inflacionado em lugares diferentes por agentes com interesses diversos". Para essas autoras, a noção de competência possui um caráter polimorfo, e que sua força social advém de sua plasticidade e das idéias que veicula (Tanguy \& Ropé, 1997, p. 16).

Portanto, o conceito de competência não é novo - como faz crer a literatura apologética rasteira - e passou por alterações ao longo do tempo. Entretanto, nosso objetivo não é a recuperação da historicidade desse conceito, mas apenas apreender o seu revigoramento no contexto da reestruturação produtiva, sob a égide do neoliberalismo e do toyotismo.

A noção de competência disseminou-se por diversas áreas de conhecimento (a economia, a sociologia, a educação, a psicologia, a administração etc). A competência associa-se às noções de desempenho e de eficiência, porém, nos domínios das referidas esferas possui sentidos e conotações diferentes. Para Tanguy e Ropé, existe uma tendência de outras noções, "que prevaleciam anteriormente como as dos saberes e conhecimentos na esfera educativa, ou a de qualificação na esfera do trabalho", serem substituídas pela de competência. Entretanto, as noções substituídas não desaparecem, apenas perdem "sua posição central e, associadas a competências, sugerem outras conotações" (Ibid).

Apesar de considerarmos impossível dissociar qualificação no âmbito do trabalho dos assim chamados saberes e conhecimentos na esfera educativa, pois essas coisas se articulam, nos limites deste trabalho abordaremos apenas a noção de competência na esfera do trabalho, ou seja, como qualificação. 
No universo empresarial, o modelo de competências aparece como um termo técnico cognitivo associado a (know-how e performance). Podendo-se mesmo, segundo Stroobants (1997, p. 142) afirmar sua vinculação à famosa trilogia "saberes, savoir-faire, saber-ser", pois é a esse trio que a forma ou grade das competências visa atingir. Para essa autora, as "competências mobilizadas" de forma sistemática impressionam pela novidade e não pelo conteúdo.

As chamadas novas competências profissionais, caracterizam-se por uma polissemia, opacidade e plasticidade, pois, não há unanimidade sobre quais saberes podem ser designados como competências, já que "não são os saberes designados que permitem caracterizar essas abordagens, mas o raciocínio no qual elas se inserem..." (Stroobants, p. 137).

Entretanto, se "não há unanimidade sobre a definição das competências progressivamente invocadas", não significa que elas perdem importância, pois, "há uma maneira geral de caracterizá-las por tipo de saber e, sobretudo, por um corte típico desses saberes" (Ibid, p. 140).

Geralmente "o savoir-faire subdivide-se em uma série de módulos que correspondem a tarefas ou a funções diferentes". Essas tarefas ou funções concretizam-se em saberes "saber-agir" "saber-transformar". A pedagogia e/ou ideologia das competências impõe o chamado padrão de "polivalência e multifuncionalidade, de controle de qualidade e de manutenção possível para cada categoria de trabalhadores e tipos de empresa" (Hirata, 1994, p. 130).

Entende-se então que as competências são atributos do indivíduo e não do posto de trabalho, já que com a exigência do trabalhador multifuncional e polivalente não se pode mais pensar o trabalho a partir do posto.

Portanto, a noção de competência é uma redefinição da qualificação profissional, no complexo de reestruturação produtiva, capaz de promover um rompimento entre as exigências da qualificação que se voltava para os postos de trabalho, onde imperava a rotina e a monotonia e o aprendizado profissional era para toda a vida. Impõe-se novas exigências de conhecimentos ao trabalhador, que deve preparar-se inclusive para mudar de profissão ao longo de sua vida. As assim chamadas competências juntamente com a denominada empregabilidade formam a ideologia da acumulação flexível fundada nos princípios e nexos organizacionais do toyotismo que é a forma de ser hegemônica da produção do capital no contexto da mundialização. A noção de competências é a forma funcionalista com que o capital arquiteta a participação manipulatória do trabalho polivalente e multifuncional - capturando sua subjetividade, levando ao extremo a alienação e o estranhamento do indivíduo e o fetichismo social.

Competência é inseparável da ação e os conhecimentos teóricos e/ou técnicos são utilizados de acordo com a capacidade de executar as decisões que a ação sugere. A competência é a capacidade de resolver um problema em uma situação dada. A competência baseia-se nos resultados (Tanguy e Ropé, Apud Deluiz, 1996, p. 7). ${ }^{\text {vi }}$

Além do que, o conjunto de competências, com ênfase no indivíduo, para além das competências técnicas, organizacionais, metódicas, comunicativas e sociais que já seriam muita coisa, exige ainda que o trabalhador possua competências comportamentais, quais sejam: "iniciativa, criatividade, vontade de aprender, abertura às mudanças, consciência da qualidade e das implicações éticas do seu trabalho, implicando no envolvimento da subjetividade do indivíduo na organização do trabalho" (Deluiz, 1996, p. 6).

O assim chamado modelo das competências é a forma de organização do trabalho flexível, que não permite mais que o trabalhador seja qualificado de forma adestrada para o cumprimento de tarefas prescritas, como ocorria sob a organização do trabalho no 
fordismo, em que as tarefas eram previamente descritas e codificadas pela gerência. $\mathrm{O}$ modelo das competências desenvolvido pela produção flexível exige do trabalhador uma qualificação real, compreendida como um conjunto de competências e habilidades, saberes e conhecimentos, "que provêm de várias instâncias, tais como, da formação geral (conhecimento científico), da formação profissional (conhecimento técnico) e da experiência de trabalho e social (qualificações tácitas)" (Ibid).

Para essa autora numa situação concreta de trabalho, o trabalhador põe em ação um conjunto de competências, que articula "vários saberes oriundos de várias esferas (formais, informais teóricos, práticos, tácitos) para resolver problemas e enfrentar situações de imprevisibilidade, a mobilização da inteligência para fazer face aos desafios do trabalho constituem características desta qualificação real" (Ibid.).

O modelo de competências cria a ilusão segundo a qual há ganhos para os trabalhadores, pois, ao contrário do que acontecia antes, o adestramento dá lugar ao trabalho comunicativo e interativo, elevando o grau de subjetividade dos trabalhadores ao exigir níveis mais elevados de abstração, criatividade, dinamismo, comunicação etc. Os autores que enaltecem esse processo "não percebem" que nessa nova sociabilidade, ocorre uma captura da subjetividade, capaz de elevar o processo de subsunção real do trabalho ao capital.

Para Helena Hirata, o modelo de competências, assim como o conceito de empregabilidade, são termos ideológicos-políticos que, se firmaram primeiro na França, podendo ser considerados sinônimos, pois, para ambos a centralidade da qualificação está no indivíduo.

Analisando o surgimento do modelo de competência, Hirata constata que o mesmo é resultado da evolução do debate acerca da qualificação profissional. Após vincular o modelo de competência como a forma assumida pelas qualificações no "novo modelo produtivo", que seria o "modelo empresarial japonês", ou seja, o toyotismo, a autora afirma que:

a competência é uma noção oriunda do discurso empresarial (...) Noção ainda bastante imprecisa, se comparada ao conceito de qualificação, um dos conceitoschaves da sociologia do trabalho francesa desde os seus primórdios (...) noção marcada política e ideologicamente por sua origem, e da qual está totalmente ausente a idéia de relação social, que define o conceito de qualificação para alguns autores... (Hirata, 1994, p. 132).

Ferretti (1997, p. 258) após tecer considerações gerais acerca do problema, afirma que "o conceito de competência representa a atualização do conceito de qualificação, segundo as perspectivas do capital, tendo em vista adequá-lo às novas formas pelas quais este se organiza para obter maior e mais rápida valorização".

Portanto, com base em Ferretti, podemos afirmar que o modelo de competência é a forma assumida pela qualificação do trabalhador no complexo de reestruturação produtiva, sob a era da universalização dos princípios e nexos organizacionais do toyotismo. Afinal, segundo afirma esse autor, é a produção integrada e flexível que determina as necessidades do capital, sempre na perspectiva do processo de valorização, produzindo um progressivo "deslocamento da importância anteriormente atribuída à qualificação formal e ao saber técnico (...) para uma outra dimensão, resumida na expressão 'saber ser', na qual se confundem/articulam/mobilizam saberes, comportamentos, racionalidade orientada para fins..." (Ferretti, 1997, p. 258).

Portanto, é considerado qualificado na lógica do modelo de competências, que foi incorporado de forma acrítica pelo MTE, nos governos de Fernando Henrique Cardoso, o 
trabalhador que possuir 'mais do que um 'estoque de saberes' - 'saber-fazer', 'saber-ser' aplicáveis ao trabalho, a qualificação", pois o modelo de competências, inclui, "necessariamente, a capacidade de enfrentar o imprevisto e o imprevisível, de ir além do domínio de tarefas prescritas". Pois, o mercado exige que "a bagagem de conhecimentos e habilidades tenderia a perder importância, valorizando-se, em escala crescente a capacidade de domínio ou condução de situações imprevistas - 'acontecimentos' ou "eventos"” (Brasil, 1999c, p.18).

Para o MTE, havia necessidade de investir na qualificação do trabalhador, pois o contexto da reestruturação produtiva estaria a exigir

novas competências, entendidas como capacidade de diagnóstico e intervenção em tempo real; não basta agir rapidamente; é preciso decidir quem e o que fazer. (...) é necessário que o trabalhador ative ou mobilize todo um background de conhecimentos, tácitos ou formais, que o habilitem a fazer diagnósticos, propor soluções e tomar medidas em cadeia de decisões cada vez mais curtas (Brasil, 1999c, p.18).

Portanto, de acordo com o MTE/SPPE, no contexto da reestruturação produtiva as empresas passam a exigir da força de trabalho novas competências, entendido como o conjunto de conhecimentos, atitudes, habilidades e atributos que tornam o trabalhador polivalente, capaz de diagnosticar e intervir em tempo real, porém, "não basta agir rapidamente; é preciso decidir quem e o que fazer" (Ibid). Afinal, as transformações na produção e nas relações de trabalho fazem com que: “A qualificação deixe de ser entendida como capacidade de realizar tarefas/operações, passando a se definir como capacidade de ação e reação diante de eventos imprevisíveis, em sua grande maioria" (Ibid).

Entretanto, não basta apenas possuir competência técnica, é necessário também que o trabalhador possa mobilizar os conhecimentos tácitos demandados pelas empresas. Segundo o MTE/SPPE o mercado passou a exigir um trabalhador competente, polivalente, e reclama o desenvolvimento integral do indivíduo, que tem que ser "trabalhador $e$ cidadão, competente e consciente" (Brasil, 1999b, p. 26).

Os ideólogos do PLANFOR partiram do pressuposto que o desenvolvimento das referidas competências seriam capazes de garantir a empregabilidade do indivíduo. A empregabilidade, que como vimos, é entendida como a capacidade do indivíduo responder às necessidades de manter-se no emprego ou, se estiver desempregado conseguir emprego ou ser criativo (sic) para obter renda de forma empreendedora. Nesta perspectiva, a busca das referidas competências, através da incorporação das atitudes, atributos e habilidades deve ser permanente, pois só assim o trabalhador poderá se manter em condições de empregabilidade, ou seja, apto para conseguir manter-se no emprego/empregar-se ou então viver de forma criativa sem emprego, buscando outras formas de trabalho e renda.

Portanto, a noção de competência foi entendida pelo MTE/SPPE, durante a era do tucanato, como uma nova dimensão da qualificação, pois afirma haver uma "dimensão da qualificação como competência", que representa:

...mais que um 'estoque de saberes' - 'saber-fazer' e 'saber-ser' aplicáveis ao trabalho, a qualificação passaria a incluir, necessariamente, a capacidade de enfrentar o imprevisto e o imprevisível, de ir além do domínio de tarefas prescritas (...) ou seja, a bagagem de conhecimentos e de habilidades tenderia a perder importância, valorizando-se, em escala crescente, a capacidade de domínio ou condução de situações imprevistas - 'acontecimentos' ou 'eventos'... (Brasil, 1999b, p 18). 
Partindo do pressuposto que no contexto da reestruturação produtiva, as empresas passam a valorizar "novas competências, entendidas como capacidade de diagnóstico e intervenção em tempo real", o Ministério do Trabalho e Emprego afirmou que:

...A qualificação deixa de ser entendida como capacidade de realizar tarefas/operações, passando a se definir como capacidade de ação e reação diante de eventos imprevisíveis, em sua grande maioria. Para tanto, não basta a simples competência técnica, mas é necessário que o trabalhador ative ou mobilize um background de conhecimentos, tácitos ou formais, que o habilitem a fazer diagnósticos, propor soluções e tomar medidas em uma cadeia de decisões cada vez mais curtas (Ibid).

Portanto, para o MTE/SPPE, o objetivo do PLANFOR era responder à exigência de formar para além da competência técnica, ou seja, ele tem a missão de qualificar trabalhadores capazes de mobilizar os conhecimentos tácitos ou formais demandados pelas empresas. Busca-se, portanto, a qualificação do trabalhador competente e polivalente, exigido pelo mercado, proclamando o desenvolvimento integral do indivíduo, que deve ser trabalhador e cidadão, competente e consciente. Afinal, segundo o MTE/SPPE, a competência individual garante a competência coletiva exigida pelo setor produtivo.

O MTE/SPPE partiu do pressuposto que as inovações tecnológicas e as novas formas de gestão e organização do trabalho colocam em crise o saber técnico, de tipo taylorista-fordista, pois, no contexto da reestruturação produtiva o foco deixa de ser o posto de trabalho, passa a se exigir uma qualificação profissional centrada na competência. Apostou-se na necessidade de desenvolvimento das habilidades voltadas para a qualificação, mas expandindo-se para as que formam a competência do trabalhador. Para SPPE, competência é um conceito mais elástico, que se forma ao longo da vida do trabalhador, seja em cursos formais ou informais, na escola ou no trabalho. Nesse sentido, as habilidades devem relacionar-se não apenas ao saber-fazer, mas aos saberes (conhecimentos), ao saber-ser (atitudes), e ao saber-agir (práticas no trabalho), que "implicam, pois, dimensões variadas: cognitivas, motoras e atitudinais" (Brasil, 1996e, p. 21).

A noção de competência representa um aumento do poder e da força capital, é a expressão de uma nova fase da subsunção real do trabalho ao capital. Representa também uma nova correlação de forças entre as forças produtivas, calcada numa relação individualizada entre empregadores e empregados, pois,

À luz de processos mais amplos, a opção pelo modelo de competência (na acepção empresarial) estaria ancorada numa lógica de recomposição da hegemonia do capital, onde a ressignificação da qualificação e das estratégias de formação profissional fazem parte de um processo de ressocialização e aculturação da classe trabalhadora, tendo por função reintegra-la aos novos modelos de produção e gestão do capitalismo em sua fase de transnacionalização (Manfredi, 1998, p. 37).

Segundo o MTE/SPPE, as atitudes e habilidades voltadas para a formação da competência devem seguir a mesma configuração do processo de educação contínua, ou seja, tem que ser permanente ao longo de toda a vida do trabalhador. Afirma-se inclusive que as "habilidades básicas, específicas e de gestão podem ser desenvolvidas em qualquer momento da vida de uma pessoa" (Ibid). 
Nos diversos documentos do MTE/SPPE sobre o PLANFOR, o pressuposto fundamental é que a qualificação profissional precisa estabelecer seu foco na empregabilidade. Afinal, "mais agonizante que estar desempregado, é ser um desempregado qualificado", ou seja, qualificado sem competência ou criatividade para desenvolver a empregabilidade de forma criativa e empreendedora. Por isso, toma-se como premissa da política de educação profissional, já na gênese do PLANFOR, a empregabilidade voltada para "três fatores inter-relacionados: investimentos geradores de trabalho, serviços de intermediação eficientes e educação contínua do trabalhador" (Brasil, 1995e, p. 5).

Elenice Leite, que foi secretária adjunta da SEFOR/MTb, entre 1995-98, analisando a tendência evolutiva de inovações tecnológicas em empresas líderes em alguns setores da indústria brasileira, concluiu que as empresas estão exigindo maior nível de qualificação, que se expressa em aprendizagem contínua em dois níveis: "da organização como um todo, entendida como capacidade de adaptação, mudança nos produtos, processos, equipamentos, funções, formas de gestão; dos agentes produtivos, desafiados a aprender, desenvolver-se e renovar-se, por meio de mecanismos formais e não-formais" (Leite, 1998, p. 2).

Afirmando que como "reflexo da crescente globalização e inserção do país na economia mundial", o mundo da produção estaria exigindo:

um novo perfil e novo conceito de qualificação, que vai além do simples domínio de habilidades motoras e disposição para cumprir ordens, incluindo também, ampla formação geral e sólida base tecnológica. Não basta mais que o trabalhador saiba 'fazer'; é preciso também 'conhecer' e, acima de tudo, 'saber aprender' (Ibid., p. 3).

Em um texto de 1997, Leite apresenta uma lista de novas competências, que "orientam-se também pela busca de cultivar e difundir uma 'nova mentalidade', calcada em conceitos como 'valorização, envolvimento e participação' do trabalhador". Eis os novos atributos valorizados segundo Leite:

i. operação de novos equipamentos/sistemas e/ou aplicação de novas técnicas com eficiência e segurança; ii. mentalidade de melhoria contínua, geral e individual; motivação e participação; iii. conhecimento do produto e do processo; iv. valores de qualidade, produtividade e competitividade; v. trabalho em equipe; relacionamento no grupo; vi. conhecimentos teóricos e aplicados em matemática, geometria, controle de qualidade, eletrônica (aplicada à mecânica), física (velocidade, corte, dureza de materiais), assistência técnica, manutenção (também para operadores); vii. leitura e interpretação de ordens de fabricação, desenhos, gráficos, tabelas; viii. raciocínio, resoluções de problemas; ix. disposição para trabalhos novos, complexos, diversificados; $\mathbf{x}$. atitude geral mais aberta e favorável a mudanças (Leite, 1997, p. 152).

Para Leite esses atributos são necessários, pois na perspectiva da empresa não basta mais contar com o típico "operário-padrão" que estava sempre pronto para "vestir a camisa da empresa". O contexto da reestruturação produtiva exige que o trabalhador possua competência e capacidade para, além de "vestir a camisa da empresa", de "pensar pela empresa". Razão pela qual a "qualificação" não é mais definida como "estoque de 
conhecimentos/habilidades", "mas sobretudo como competência ou capacidade de agir, intervir, decidir em situações nem sempre previstas ou previsíveis" (Ibid.).

\section{O conceito de empregabilidade e o revigoramento da teoria do capital humano}

Embora a assim chamada teoria do capital humano tenha vindo ao mundo antes da explosão da crise do capital sob a regulação do taylorismo-fordismo, podemos afirmar que é no contexto desta crise que ela se fortalece e dissemina. ${ }^{\text {vii }}$ Formulada originalmente nos anos sessenta por Theodore Schultz, Gary Becker e Frederick Harbison, esta teoria pautase pela preocupação com a relação entre a educação e o crescimento econômico. Para os adeptos desta teoria é necessário investir na formação e educação dos trabalhadores, no sentido de fazer frente às demandas da denominada sociedade pós-industrial.

A teoria do capital humano deriva-se da teoria econômica neoclássica, sendo ao mesmo tempo, do ponto de vista ideológico "uma atualização do axioma liberal do indivíduo livre, soberano e racional" (Cattani, 1997, p. 35). Esse pressuposto reaparece, visando redefinir as relações de trabalho na empresa, assim como, o papel a ser exercido pela educação ante a crise instaurada na produção.

Portanto, a teoria do capital humano constitui-se em uma justificativa do capital diante das enormes diferenças no desenvolvimento econômico-social entre países sob o controle do capital no contexto da guerra fria. Além disso, havia o problema da extrema miséria de grande parte da população nos países do terceiro mundo.

A teoria do capital humano (TCH) veio ao mundo no contexto da chamada "Aliança para o Progresso", um mega projeto do governo norte americano, na gestão Kennedy, para o desenvolvimento da América Latina, no sentido de levá-la a alcançar os níveis de desenvolvimento dos países avançados, mediante um esforço em inversões produtivas, considerando-se a educação como meio importante para tal feito. Portanto, a TCH é uma ideologia marcada pela Guerra Fria, afinal, é após a revolução cubana e o conflito americano x soviético que os EUA se propõe a criar a ilusão do desenvolvimento da América Latina, que será marcada pela intervenção militar em grande parte dos países.

Naquele contexto os economistas redescobriram a importância atribuída por Adam Smith à formação da força de trabalho. Ganha importância a noção de que o desenvolvimento dos países avançados, não se explica apenas pelos fatores clássicos terracapital-trabalho, isso porque segundo os cálculos dos econometristas, esses fatores eram insuficientes para explicar o crescimento dos produtos. Surge então uma explicação não clássica que atribui à margem de crescimento não explicados pela concepção clássica a fatores residuais que, "incluíam inicialmente uma série de variáveis, tais como organização, tecnologia, educação, porém gradualmente os estudos se reduziram a explicar a incidência desta última" (Finkel, 1994, p. 251).

A lógica da TCH espraiou-se pelo mundo, influenciando reformas educacionais, visando à conformação da educação profissionalizante na perspectiva do capital, além de difundir a idéia segundo a qual a existência de países "subdesenvolvidos" e de massas de miseráveis nesses países é decorrência do investimento não adequado na educação. $\mathrm{O}$ pressuposto fundamental da TCH é que o investimento na educação é fator decisivo para o processo de desenvolvimento econômico, sendo o índice de crescimento do capital humano considerado um dos indicadores do desenvolvimento econômico. No plano individual essa teoria considera que a profissionalização, através da escola, garante aos indivíduos a aquisição de aptidões e habilidades pessoais para competir no mercado de trabalho e assim melhorarem sua renda (Finkel, 1996, p. 251). 
Países como o Brasil, por exemplo, mudaram radicalmente a legislação e a estrutura educacional, mexendo com a vida de milhões de pessoas para se adequar aos preceitos da referida teoria, acreditando que o país entraria em uma fase de contínuo desenvolvimento, até atingir o status de país desenvolvido.

Frigotto (1989, p. 16-7) afirma que a teoria do capital humano vincula-se à economia neoclássica e ao positivismo e que os pressupostos de seu estatuto teórico constitui-se em dois sentidos básicos, quais sejam: $1^{\circ}$ uma teoria do desenvolvimento e $2^{\circ}$ uma "teoria da educação". Nesse sentido, afirma que a "teoria do desenvolvimento concebe a educação como produtora de capacidade de trabalho, potenciadora de trabalho e, por extensão, potenciadora de renda, um capital (social e individual), um fator do desenvolvimento econômico e social" (Frigotto, 1989, p. 16). Enquanto que o segundo sentido, a teoria da educação, articulado com o primeiro, pressupõe que:

a ação pedagógica, a prática educativa escolar reduzem-se a uma questão técnica, a uma tecnologia educacional cuja função precípua é ajustar requisitos educacionais a pré-requisitos de uma ocupação no mercado de trabalho de uma dada sociedade. Trata-se da perspectiva instrumentalista e funcional de educação (Ibid).

No contexto da reestruturação produtiva e da ofensiva neoliberal, a teoria do capital humano se revigora, se revitaliza e se apresenta como uma neoteoria. O economista americano Gary Becker, prêmio Nobel de Economia em 1992, apoiou-se na teoria do capital humano para sustentar que as diferenças salariais nas empresas são de responsabilidade dos próprios trabalhadores. Para Becker haveria uma racionalidade utilitarista, fundado no cálculo racional que orientaria toda a vida social, quer seja econômica, casamento, amizades, religião ou lazer (Cattani, 1997, p. 37). Quanto à educação, "essa versão do utilitarismo racional supôs que a formação aumentaria a produtividade" (Ibid., p. 37). Ou seja: "Quanto mais o indivíduo investisse na autoformação, na constituição do seu 'capital pessoal', tanto mais valor de mercado teria" (Ibid). Como os dotes individuais são diferenciados, e a formação de uns indivíduos demanda mais tempo, esforço e investimento financeiro que a de outros, podendo os rendimentos futuros não cobrir os gastos com a formação, continuar ou não os estudos constitui-se em decisão de foro íntimo, pois, conforme depreende Cattani da leitura de Becker, "cada indivíduo investiria até o limite no qual o investimento deixasse de ser rentável" (Ibid).

As concepções que sustentam as reformas na educação profissional dos anos 90, fundamentalmente as do PLANFOR, vinculam-se à teoria do capital humano, senão em sua forma original, mas através de um revigoramento daquela ideologia.

Portanto, haveria uma neoteoria do capital humano, adaptada ao contexto da reestruturação capitalista, pois o conceito de empregabilidade tão declamada pelas políticas educacionais, integra o rol de conceitos flexibilizantes neoliberais. A empregabilidade, conceito liberal que emergiu no contexto da reestruturação produtiva, segundo o qual o indivíduo deve cuidar de si mesmo é um pressuposto ideológico inspirado na teoria do capital humano. Gentili $(1999$, p. 88$)$ afirma que

O apelo à empregabilidade, e seu uso numa neo-teoria do capital humano cujo conteúdo tem-se metamorfoseado com as novas condições de acumulação do capitalismo globalizado, (...) a tese da empregabilidade recupera a concepção individualista da teoria do capital humano, só que acaba com o nexo que aquela estabelecia entre o desenvolvimento do 
capital humano individual e o capital humano social: as possibilidades de inserção de um indivíduo no mercado dependem (potencialmente) da posse de um conjunto de saberes, competências e credenciais que o habilitam para a competição pelos empregos disponíveis (a educação é, de fato, um investimento em capital humano individual); só que o desenvolvimento econômico da sociedade não depende hoje de uma maior e melhor integração de todos à vida produtiva (a educação não é, em tal sentido, um investimento em capital humano social).

Ana Teixeira também estabelece o vínculo direto entre a empregabilidade com o neoliberalismo, afirmando que

Advindos da retórica neoliberal, vão ganhando visibilidade os conceitos de competência individual, empregabilidade e a constituição de um 'espírito' de iniciativa, lealdade e comprometimento, referências que passam a nortear as políticas educacionais e um sem número de programas/projetos de (re)qualificação profissional direcionados aos trabalhadores, agora chamados a se transformarem em 'novos homens' (Teixeira, 1998, p. 167).

Portanto, no contexto da reestruturação produtiva há uma ressignificação da Teoria do Capital Humano, ou na acepção de (Duarte, 2001, p. 29) um revigoramento dessa teoria, que direciona as políticas de educação profissional no Brasil, como é o caso, por exemplo, do PLANFOR. Em contraposição a essa lógica perversa do neoliberalismo, algumas análises apontam o reducionismo presente nessas políticas.

Frigotto (1998, p.14) destaca que

os processos educativos e formativos, que ao mesmo tempo são constituídos e constituintes das relações sociais (...), passam por uma ressignificação no campo das concepções e das políticas. Estreitam-se ainda mais a compreensão do educativo, do formativo e da qualificação desvinculando-os da dimensão ontológica do trabalho e da produção, reduzindo-os ao economicismo do emprego e, agora, da empregabilidade.

A ideologia dominante, no contexto da reestruturação produtiva, preconiza uma redefinição da Teoria do Capital Humano, uma neoteoria, na medida em que articula educação profissional e empregabilidade. Na perspectiva das instituições empresariais (CNI, FIESP) e de seu sistema de formação profissional (SENAI, SENAC) prevalece a concepção de que o novo paradigma produtivo exige novos perfis profissionais que se resumem em dois conceitos: polivalência e flexibilidade. Segundo Catani et al (2000, p. 3) essa determinação está posta

com maior ou menor intensidade, para os trabalhadores de todos os ramos e para todas as instituições educativas e formativas, especialmente as escolas e as universidades. Além disso, o desenvolvimento dessa polivalência e flexibilidade profissional (profissional multicompetente) incluiria a identificação de habilidades cognitivas e de competências sociais requeridas no exercício das diferentes profissões, bem como nos diferentes ramos de atividade. Inclui também o repensar dos perfis profissionais e dos programas de formação, qualificação e requalificação de diferentes instituições formadoras, tais como escolas, universidades, sindicatos, empresas e ONGs. 
As agências multilaterais (Banco Mundial, BID, UNESCO, CEPAL, OIT, etc...) disseminam por toda parte esta neoteoria, fazendo supor que por meio da educação básica e profissional o indivíduo garante a sua empregabilidade. Essas instituições desconsideram todo o contexto macroeconômico e apregoam que o investimento na educação básica aumenta a possibilidade das nações emergentes reverterem as desigualdades sociais.

Há, portanto, no contexto da reestruturação produtiva uma intensificação do pensamento liberal, que retoma os pressupostos da teoria do capital humano. Pressupondo que a qualificação e o treinamento para o exercício profissional são suficientes para garantir a empregabilidade e/ou a elevação da renda do trabalhador, no contexto da mundialização do capital. Entendemos que isso é um pressuposto ideológico-idealista que desconsidera todas as determinações econômicas, políticas e sociais que recaem sobre o trabalhador. É essa ideologia que norteia a concepção de qualificação profissional do PLANFOR, que pressupõe a qualificação como treinamento profissional, voltada para o desenvolvimento de competências adequadas para garantir a empregabilidade do trabalhador, assim como a elevação de seu rendimento.

Em texto que se constitui em uma apologia às políticas do governo FHC, voltadas para a pobreza, que esteve muito tempo disponibilizado no site do MTE, Rios-Neto e Oliveira, partem do pressuposto que no Brasil "a exclusão é atenuada pela alta flexibilidade", que permite a absorção da "mão-de-obra" pelo setor informal através da rotatividade. Analisando a contribuição do PLANFOR para atenuar a exclusão, afirmam que:

Neste contexto, a acumulação de capital humano através da escolaridade e da formação profissional são requisitos essenciais para a redução da privação e desigualdade, como também o é a necessidade de redução na taxa de rotatividade (Rios-Neto e Oliveira, s/d, p. 4).

Portanto, no contexto da reestruturação produtiva observa-se um revigoramento da teoria do capital humano, através do modelo da competência e da ideologia da empregabilidade, que se propagam pelo mundo por meio das ações políticas das agências multilaterais (FMI, BIRD, BID, UNESCO, OIT/CINTERFOR, etc.). No Brasil, os pressupostos do modelo das competências e da ideologia da empregabilidade nortearam as reformas educacionais conduzidas pelo MEC e o Programa Nacional de Formação Profissional - PLANFOR, do Ministério do Trabalho.

A teoria do capital humano, em seu revigoramento, no contexto do mundialização do capital, reaparece recheada com os conceitos de competência, empregabilidade $e$ sociedade do conhecimento.

Faremos a seguir algumas reflexões acerca da visão das instituições empresarias, das centrais sindicais e também do Estado, sobre o complexo de reestruturação produtiva e a necessidade de uma política pública de formação profissional. Isso se faz necessário, tendo em vista que o PLANFOR, apesar de ser gerido pela SPPE/MTE, é um Programa de responsabilidade tripartite e paritário, constituindo-se num espaço de disputa de hegemonia política, segundo a CUT, mas, sobretudo de disputa por recursos financeiros. Como pretendemos fazer a crítica do tripartismo paritário, faz-se necessário discutir os pressupostos dos atores envolvidos.

\section{REFERÊNCIAS}

Revista HISTEDBR On-line, Campinas, n. Especial, p.162-180, mai.2009 - ISSN: 1676-2584 
ALVES, Giovanni. O novo (e precário) mundo do trabalho: Reestruturação produtiva e crise do sindicalismo. São Paulo: Boitempo, 2000.

ANTUNES, Ricardo. Os sentidos do trabalho - ensaio sobre afirmação e a negação do trabalho. São Paulo: Boitempo, 1999.

ARAÚJO, Ronaldo Marcos de Lima. As novas "qualidades pessoais" requeridas pelo capital. Trabalho \& Educação. Núcleo de Estudos sobre Trabalho e Educação/UFMG, n 5, p. 18-33, 1999.

BRASIL. Educação Profissional: um projeto para o desenvolvimento sustentado. SEFOR/MTb, FAT/CODEFAT, 1999a, http://mte.gov.br.

BRASIL. Habilidades uma questão de competências? Brasília: MTb/SEFOR, FAT/CODEFAT, 1996.

BRASIL. Plano de Ação - Um Compromisso com a Mudança 1996-1998. Brasília: SEFOR/MTb, 1999b, http://mte.gov.br.

BRASIL. Política para a educação profissional: cooperação MEC/MTb. Brasília: MTb/SEFOR/MEC/SPPE, 1995.

CASTRO, Ramón Peña. A construção social do emprego e da qualificação. Texto apresentado na Reunião da Associação Nacional de Pós-Graduação e Pesquisa em Educação. Caxambu, mimeo, 2001.

CATANI, Afrânio Mendes et al. Mudanças no mundo do trabalho e reforma curricular dos cursos de graduação no Brasil. Caxambu, Anped, 2000, in: http://www.anped.org.br/

CATTANI, Antonio David (org.). Trabalho e Tecnología: Diccionario crítico. Petrópolis: Vozes, 1999.

DIAS, Edmundo Fernandes. A liberdade (im)possível na ordem do capital: reestruturação produtiva e passivização. Campinas-SP: IFCH/Unicamp, 1999.

distintas leituras da obra de Marx. São Paulo: PUC, relatório parcial de pesquisa, 2001.

DUARTE, Newton. Vigotski e o "aprender a aprender": crítica às apropriações neoliberais e pós-modernas da teoria vigotskiana. Campinas, SP: Autores Associados, 2001.

FERRETTI, Celso João. Formação Profissional e reforma do ensino técnico no Brasil: anos 90. Educação e Sociedade Campinas, nº 59, p. 225-269, 1997.

FINKEL, Lucila. La organización social del trabajo. Madrid: Perámide, 1996

FREITAS, Luiz Carlos de. Crítica da organização do trabalho pedagógico e da didática. Campinas, SP: Papirus, 2001.

FRIGOTTO, Gaudêncio. A produtividade da escola improdutiva. São Paulo: Cortez: Autores Associados, 1989.

GENTILI, Pablo. O conceito de empregabilidade. In: Avaliação do PLANFOR: uma política pública de educação profissional em debate. São Carlos: UNITRABALHO, 1999.

HIRATA, Helena. Da polarização das qualificações ao modelo da competência. In, Ferretti, C. J. et al. Novas Tecnologias, trabalho e educação: um debate multidisciplinar. $2^{a}$ ed, Petrópolis: Vozes, 1994.

LEITE, Elenice Monteiro. Reestruturação industrial, cadeias produtivas e qualificação. In CARLEIAL, Liana \& VALLE, Rogério. Reestruturação produtiva e mercado de trabalho no Brasil. São Paulo: Hucitec-Abet, p. 140-166, 1997.

LEITE, Elenice Monteiro. Reestruturação produtiva no Brasil: mudanças no mercado de trabalho e impactos sobre a qualificação profissional. Brasília: Convênio MTb/SEFORFLACSO, 1998.

PINTO, Ana Maria Rezende. Pessoas inteligentes trabalhando com máquinas ou máquinas inteligentes substituindo o trabalho humano. Trabalho e Educação, Campinas, Papirus, p. 39-44, 1994. 
qualificação profissional como construção e relações sociais: as contribuições de RAMOS, Marise Nogueira. A pedagogia das competências: autonomia ou adaptação? São Paulo: Cortez, 2001.

ROPÉ, Françoise \& TANGUY, Lucie (Orgs.). Saberes e competências: O uso de tais noções na escola e na empresa. Campinas: Papirus, 1997.

RUMMERT, Sonia Maria. Capital e trabalho convergências e divergências quanto à educação básica. Trabalho \& Educação, Belo Horizonte, NETE/UFMG, nº 4, 1999, p. 2139.

SILVA JÚNIOR, João dos R., FERRETTI, Celso J. e GONZÁLEZ, Jorge L. C. A STROOBANTS, Marcelle. A visibilidade das competências. In ROPÉ, Françoise \& TANGUY, Lucie (Orgs.). Saberes e competências: $O$ uso de tais noções na escola e na empresa. Campinas: Papirus, p. 135-166, 1997.

TEIXEIRA, Ana. Trabalho, tecnologia e educação: algumas considerações. Trabalho $e$ Educação, Belo Horizonte, NETE/UFMG, nº 4, p. 161-184, 1998.

\footnotetext{
${ }^{\text {i }}$ Doutorando em Ciências Sociais pela UNESP/Marília. Pesquisador do Grupo de Pesquisa "Estudos da Globalização", cadastrado no CNPq http://globalization.sites.uol.com.br/. Membro da Rede de Estudos do Trabalho - RET www.estudosdotrabalho.org.

ii Doutorando em Sociologia pela UNESP/Araraquara. Pesquisador Colaborador do Projeto OPT Observatório da Precarização do Trabalho: Unesp/Marília, cadastrado no CNPq. Membro da RET- Rede de Estudos do Trabalho www.estudosdotrabalho.org.

iii Neste caso, incorporamos a definição dada por Terry Eagleton (1997), que compreende o conceito de ideologia: “[...] como processo material geral de produção de idéias, crenças e valores na vida social [...] idéias e crenças (verdadeiras ou falsas) que simbolizam as condições e experiências de vida de um grupo ou classe específico, socialmente significativo" (Eagleton, 1997:38). Eagleton, Terry. Ideologia.Trad. Silvana Vieira, Luís Carlos Borges. São Paulo: Editora Unesp: Editora Boitempo, 1997.

${ }^{\text {iv }}$ A flexibilidade fundada no método produtivo just-in-time/kanban, foi desenvolvida na empresa Toyota na década de 1950, por Taichi Ohno, posteriormente disseminada no ocidente a partir de 1980. Gradativamente foram incorporados novos elementos tais como o Total Productive Maintenance - TPM (Manutenção Produtiva Total), método que visa eliminar perdas, reduzir paradas, garantir a qualidade, diminuir custos através dos contínuos processos de mudanças. Também objetiva evitar perdas de máquinas e equipamentos, perdas (acidentes) com a força de trabalho, absenteísmo e perdas de métodos (a melhor maneira de produzir). Ou ainda os 5s: Seiri: Senso de utilização. Seiton: Senso de organização. Seisō: Senso de limpeza. Seiketsu: Senso de padronização. Shitsuke: Senso de auto-disciplina. Kaizen (mudança para melhor), significa melhoria contínua, gradual, na vida em geral, pessoal, familiar, social e no trabalho.

${ }^{\mathrm{v}}$ Nos documentos oficiais pesquisados, várias foram as formas de se decifrar a sigla PLANFOR, dentre elas, Programa Nacional de Qualificação do Trabalhador, Plano Nacional de Educação Profissional, Programa Nacional de Qualificação Profissional, Plano Nacional de Formação Profissional, e Plano Nacional de Educação do Trabalhador. Utiliza-se neste trabalho o que consta da resolução n. 194/98 do CODEFAT, ou seja, Plano Nacional de Qualificação do Trabalhador, que vigorou entre 1995 a 2002.

vi Esse texto foi capturado eletronicamente, razão pela qual, a paginação não corresponde à publicação original.

vii Afinal, foi em 1979 que o economista Theodore William Schultz venceu o Prêmio Nobel de Economia, juntamente com Arthur Lewis.
}

Artigo recebido em: 08/12/2008

Aprovado para publicação em: 20/01/2009 